\title{
An Introduction to the Five-Factor Model and Its Applications
}

\author{
Robert R. McCrae \\ National Institute on Aging, NIH \\ Oliver P. John \\ University of California at Berkeley
}

\begin{abstract}
The five-factor model of personality is a hierarchical organization of personality traits in terms of five basic dimensions: Extraversion, Agreeableness, Conscientiousness, Neuroticism, and Openness to Experience. Research using both natural language adjectives and theoretically based personality questionnaires supports the comprehensiveness of the model and its applicability across observers and cultures. This article summarizes the history of the model and its supporting evidence; discusses conceptions of the nature of the factors; and outlines an agenda for theorizing about the origins and operation of the factors. We argue that the model should prove useful both for individual assessment and for the elucidation of a number of topics of interest to personality psychologists.
\end{abstract}

What are the basic dimensions of personality, the most important ways in which individuals differ in their enduring emotional, interpersonal, experiential, attitudinal, and motivational styles? Personality theorists have offered hundreds of candidates, and for decades factor analysts attempted to bring order to the resulting confusion by factoring personality scales. Instead of resolving the issue, however, these studies only contributed another layer of controversy, most familiar in the compet-

We are grateful to Michael Bond, Peter Borkenau, David Buss, Paul Costa, Donald Fiske, Lew Goldberg, Robert Hogan, and Warren Norman for comments on this manuscript, and to Stephen G. West and the associate editors of this journal for their advice and assistance on this special issue. Correspondence may be addressed to Robert $\mathbf{R}$. McCrae, Personality, Stress, and Coping Section, Gerontology Research Center, 4940 Eastern Avenue, Baltimore, MD 21224.

This article lies in the public domain because it was written for and funded by the federal government 
ing systems of Guilford, Cattell, and H. J. Eysenck. So when Tupes and Christal (1961; reprinted in this issue) found five recurrent factors in analyses of personality ratings in eight different samples, they were understandably surprised:

In many ways it seems remarkable that such stability should be found in an area which to date has granted anything but consistent results. Undoubtedly the consistency has always been there, but it has been hidden by inconsistency of factorial techniques and philosophies, the lack of replication using identical variables, and disagreement among analysts as to factor titles. (p. 12)

Despite their work-and the more widely read replication of Norman (1963) - the importance of these five factors remained hidden from most personality psychologists throughout the 1960s and 1970s. In the 1980 s, however, researchers from many different traditions were led to conclude that these factors were fundamental dimensions of personality, found in self-reports and ratings, in natural languages and theoretically based questionnaires, in children, college students, and older adults, in men and women, and in English, Dutch, German, and Japanese samples (John, 1990a). All five factors were shown to have convergent and discriminant validity across instruments and observers, and to endure across decades in adults (McCrae \& Costa, 1990). As a brief introduction to their nature, Table 1 lists definers of the positive pole of each of these factors.

This new consensus has grown rapidly. Two or three years ago, a special issue on the topic would doubtless have been filled with articles offering evidence for or against the model itself (e.g., Borkenau \& Ostendorf, 1989; Noller, Law, \& Comrey, 1987; Waller \& Ben-Porath, 1987; Zuckerman, Kuhlman, \& Camac, 1988). We will review some of that evidence here; it is also treated elsewhere (Digman, 1990; Goldberg, 1990; John, 1990a; Wiggins \& Trapnell, in press). Today we believe it is more fruitful to adopt the working hypothesis that the five-factor model (FFM) of personality is essentially correct in its representation of the structure of traits ' and to proceed to its implications for personality theory and its applications throughout psychology. This has been our guiding principle behind this special issue.

1. In this article we use phrases like "structure of traits" and "dimensions of personality" to refer to the patterns of covariation of traits across individuals, not to the organization of attributes within the individual (cf. John. 1990a, p. 96). 
If this hypothesis is correct-if we have truly discovered the basic dimensions of personality-it marks a turning point for personality psychology. Instead of the interminable disputes among competing systems that so long paralyzed the field, we could see cooperative research and cumulative findings. Instead of the redundancy that results from measuring the same construct under a dozen different names, we could see an efficient integration of the literature across many instruments. And instead of the lost insights that a haphazard selection of personality variables is likely to produce, we could see a complete and systematic pursuit of personality correlates. The FFM could provide a common language for psychologists from different traditions, a basic phenomenon for personality theorists to explain, a natural framework for organizing research, and a guide to the comprehensive assessment of individuals that should be of value to educational, industrial/organizational, and clinical psychologists.

Even its most ardent defenders do not claim that the FFM is the last word in the description of personality. There are disputes among fivefactorists about the best interpretation of the factors; there are certainly important distinctions to be made at the level of the more molecular traits that define the factors; and it is possible that there are other basic dimensions of personality. But some version of these five dimensions is at least necessary for an adequate description of individual differences, and if all personality researchers compare their preferred system to this framework, it should soon become clear whether and in what ways the model is deficient.

\section{Naming and Identifying the Factors}

The consensus that five-factorists see among themselves may be puzzling to outsiders because the "disagreement among analysts as to factor titles" that Tupes and Christal noted still plagues the field (John, 1990b). Factor names reflect historical accidents, conceptual positions, and the entrenchment that comes from a published body of literature and from published instruments. There are two prominent systems for naming the factors, one derived from the lexical tradition and one from the questionnaire tradition.

Many writers take Norman's (1963) annunciation of an "adequate taxonomy of personality attributes" derived from Cattell's reduction of natural language trait terms as the formal beginning of the FFM, and the factor numbers and names Norman chose-I: Extraversion or Sur- 


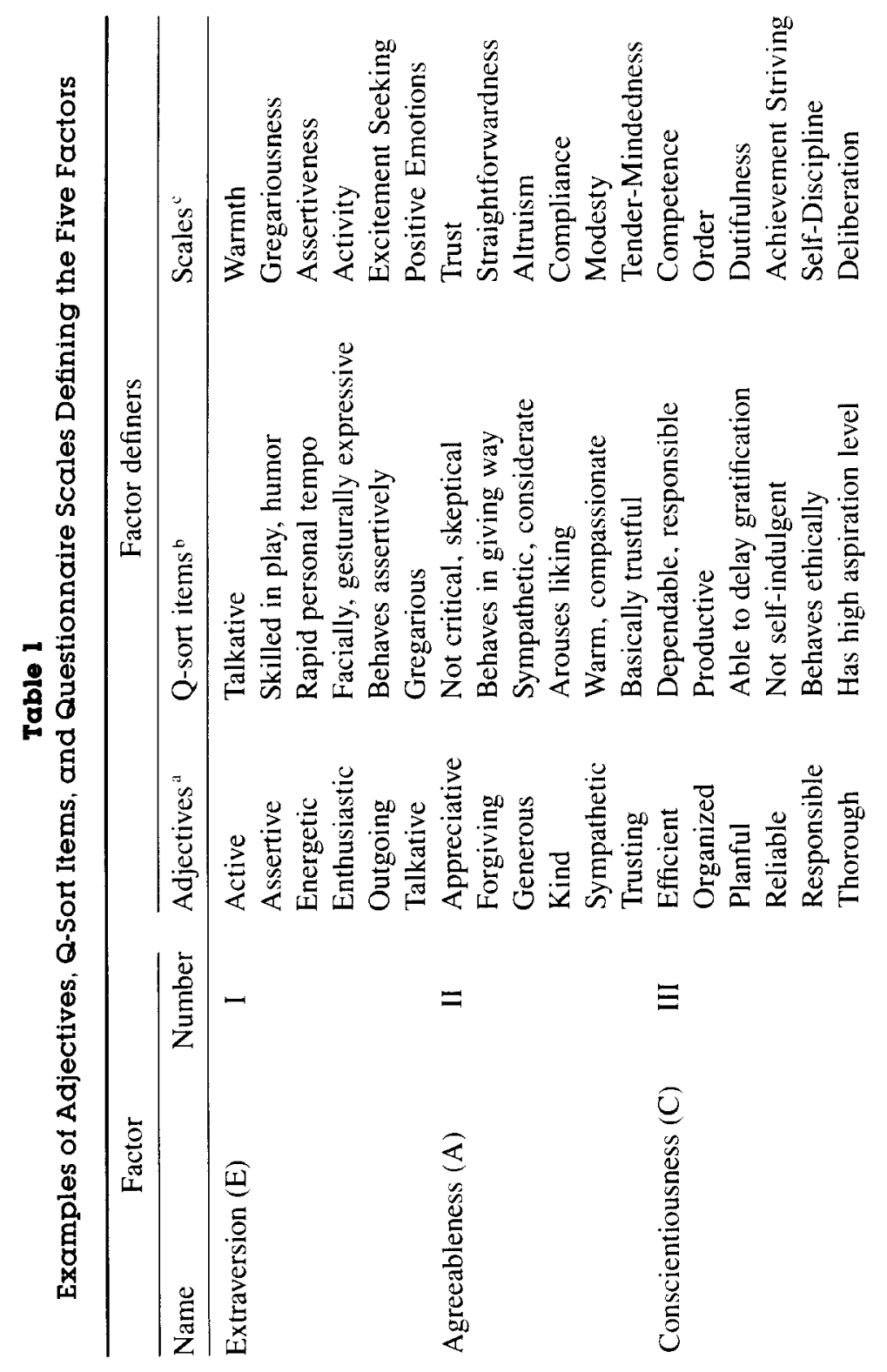




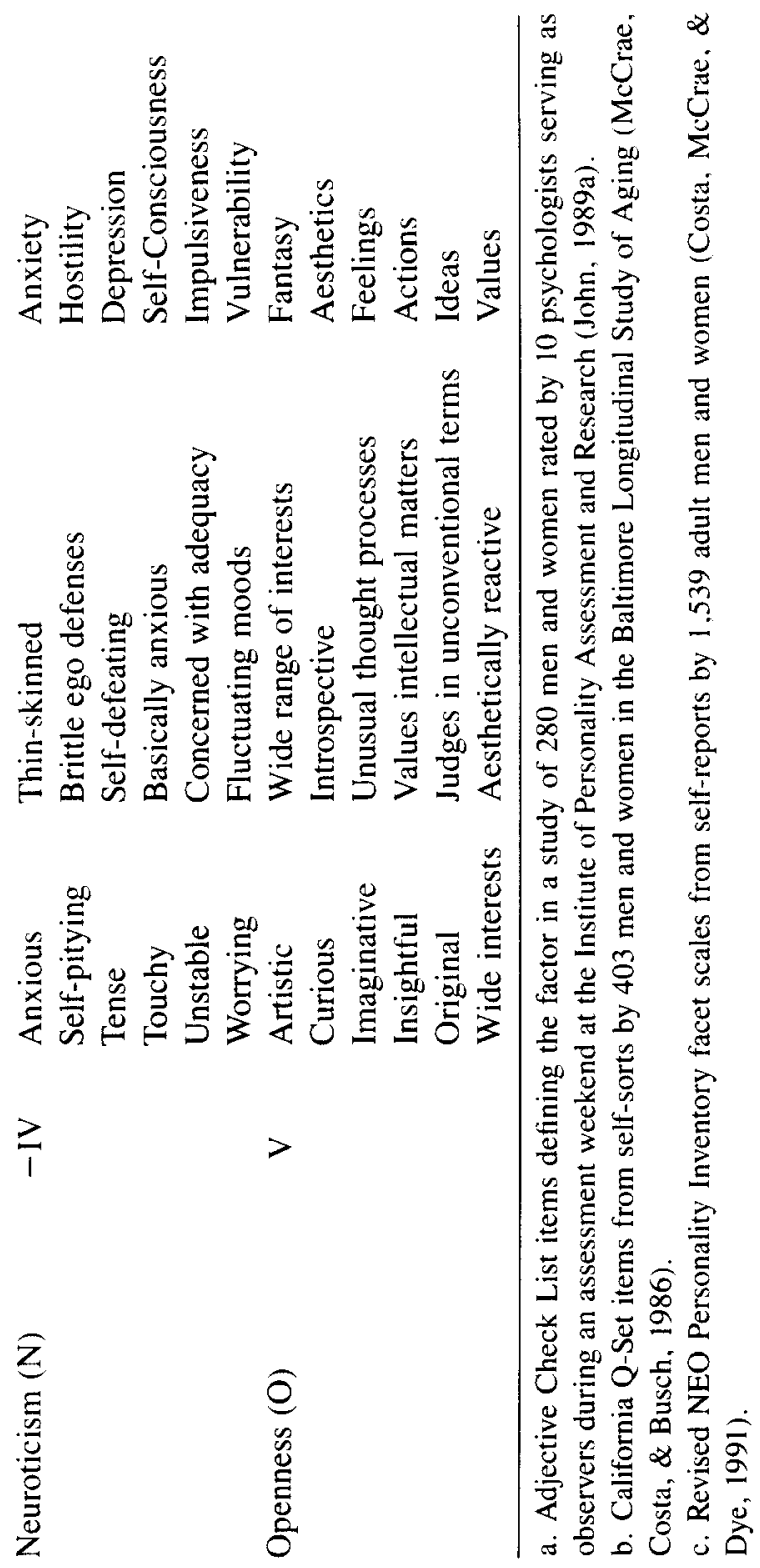


gency; II: Agreeableness; III: Conscientiousness; IV: Emotional Stability; and V: Culture - are often used. Peabody and Goldberg (1989) have noted that the order in which these factors emerged roughly parallels their representation among English language trait terms in the dictionary: Many more words can be found to describe aspects of Factors I through III than of Factors IV and V. The factor numbers, I to V, are thus meaningful designations. Roman numerals also have the advantage of being theoretically neutral; they seem to stand above the fray of disputed factor interpretations.

The second tradition that led to the modern FFM comes from the analysis of questionnaires, and particularly from the work of $\mathrm{H}$. J. Eysenck, who identified Extraversion (E) and Neuroticism (N) as major components of psychological tests. (It was Wiggins, 1968, who dubbed these the "Big Two," setting the stage for Goldberg's 1981 designation of the FFM as the "Big Five.") Costa and McCrae (1980) added a dimension they called Openness to Experience (O), and later (1985, 1989) created scales to measure Agreeableness (A) and Conscientiousness (C). A number of publications (e.g., Borkenau \& Ostendorf, 1990; Funder \& Colvin, 1988; Tellegen \& Waller, in press; Wiggins \& Pincus, 1989; Zuckerman, Bernieri, Koestner, \& Rosenthal, 1989) have adopted this nomenclature. Note that $\mathrm{N}$ corresponds to low Emotional Stability, $-I V$, and $O$ is a variant of Norman's Factor V.

If the advantage of the Norman numbers is their theoretical neutrality, the disadvantage is their low mnemonic value. Initials, originally popularized by H. J. Eysenck, are easier to interpret, and they may be less theoretically laden than full names. To those for whom Neuroticism connotes psychiatric disorder, negative affectivity (Watson \& Clark, 1984) or simply nervousness may seem more apt; all can be characterized by N. Likewise, E can also stand for energy or enthusiasm (cf. Watson \& Clark, in press); O for originality; A for affiliation (Leary, 1957) or affection (Brand, 1984), and C for constraint (Tellegen, 1982) or control (Krug \& Johns, 1986).

The claim of five-factor theorists is that these factors, singly or in combination, can be found in virtually all personality instruments, and a number of authors have compiled tables showing the putative assignment of standard personality scales or factors to the five (e.g., Brand \& Egan, 1989; Digman, 1990; Hogan, 1983; John, 1990a; see also Table 2). These tables can be extremely useful not only as a demonstration of the nature and pervasiveness of the five factors, but also as a guide to researchers and meta-analysts who need to identify alterna- 
tive measures of the same fundamental construct. Similarly, researchers sometimes interpret their own factor analyses in terms of these five (e.g., Loehlin, 1987; Lorr, 1978; Noller et al., 1987). Here, too, the communicative power of the model is exploited.

The danger is that such identifications may be wrong. Hogan (1983) classified Costa and McCrae's Openness scale as a measure of Conscientiousness; Noller et al. (1987) interpreted a factor combining liberal thinking, assertiveness, rebelliousness, and imagination as (low) A; Costa and McCrae (1976) interpreted a similar factor as O. The integrative value of the model is clearly compromised by such discrepancies.

Two approaches have been used to resolve such problems of classification. John (1990a) formalized a rational strategy: A group of 10 judges familiar with the classic literature on the FFM assigned the 300 items of Gough and Heilbrun's (1983) Adjective Check List (ACL) to one of the factors. Coefficient alpha reliabilities of the mean judgments exceeded .90 for all five dimensions. This study demonstrated that substantial interrater agreement on the content of the factors is possible, and produced lists of items that correspond to common conceptions of the five factors. McCrae, Piedmont, and Costa (1990) had raters judge the extent to which items of the California Psychological Inventory (CPI; Gough, 1987) were indicative or contraindicative of each of the five factors and analyzed CPI scales in terms of this item content. Itemby-item analysis by multiple raters increases the objectivity of rational scale interpretation.

A complementary approach is empirical: Scales or new factors can be correlated with standard measures of the five factors (e.g., Yang \& Bond, 1990). Table 2 shows some results of this approach. Briggs (this issue) describes and evaluates available measures of the factors. Ideally, researchers would include at least two standard markers of each factor to examine the replicability of results. ${ }^{2}$

\section{The Two Historical Paths to the Five-Factor Model}

\section{The lexical approach}

It is well-known that the FFM originated in studies of natural language trait terms (John, Angleitner, \& Ostendorf, 1988). In brief, Allport and

2. Routine inclusion of a measure of general intelligence would also be useful, particularly in resolving questions about the nature of Factor V (McCrae \& Costa, in press). 


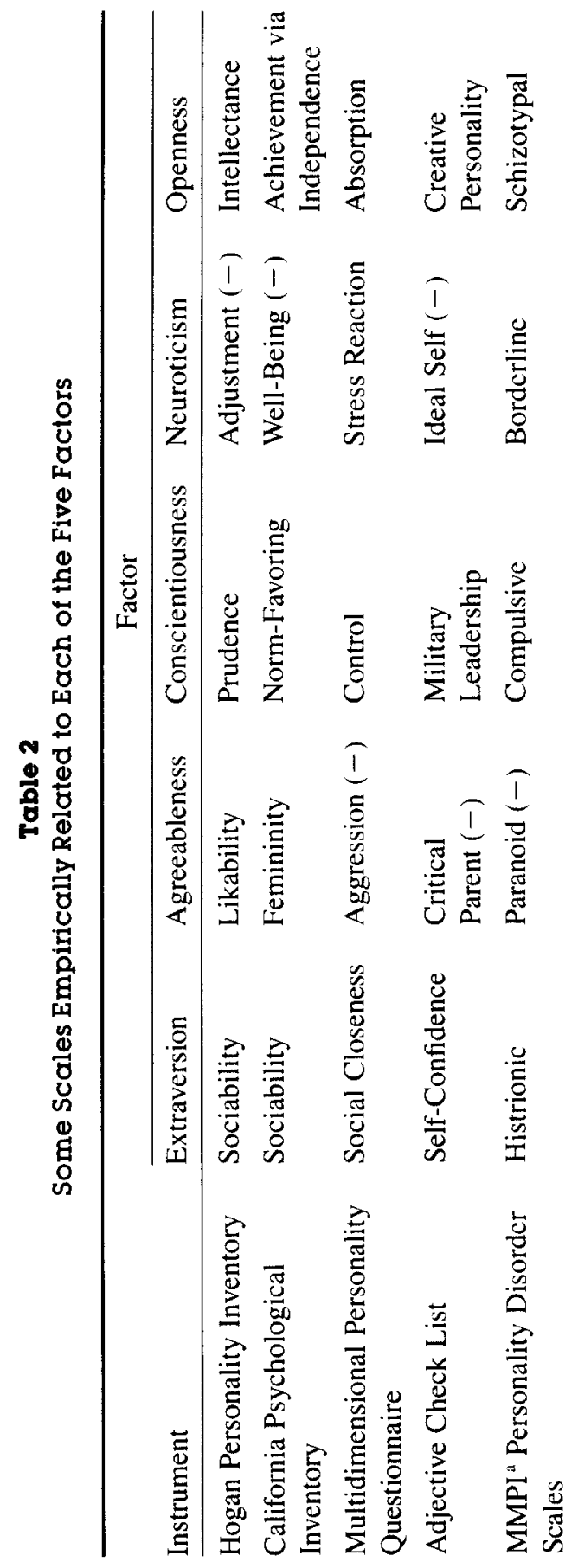




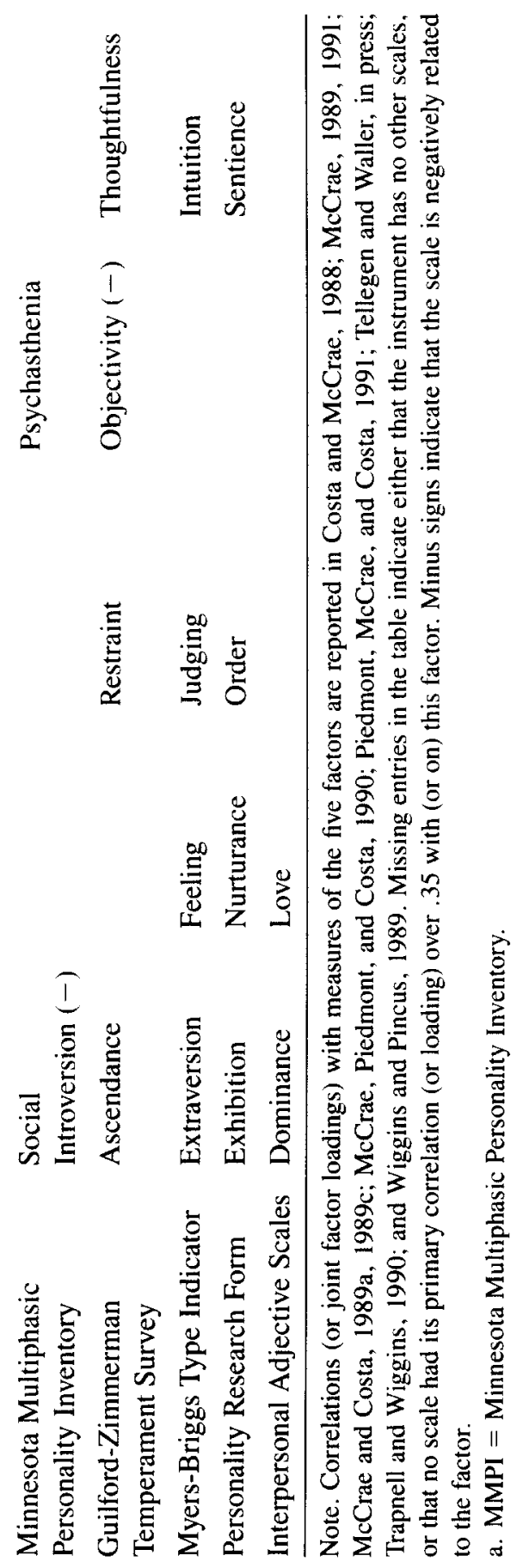


Odbert (1936) abstracted terms from a dictionary; Cattell (1946) formed them into synonym clusters and then created rating scales contrasting groups of adjectives; Tupes and Christal (1961) obtained observer ratings on these 35 scales and factored them. (Fiske, 1949, had also used a version of Cattell's rating scales in the earliest recovery of the five factors.) Norman used the best 20 rating scales from the Tupes and Christal study in his replications, and that set was subsequently used in many later studies.

Any emerging consensus on the five factors in the 1960s was quickly derailed by the controversy over implicit personality theory (reviewed by Borkenau in this issue); that controversy contributed to the demoralization of personality psychology in the 1970s, and the FFM went into exile: The most important new studies were the cross-cultural replications by Bond (1979; Bond, Nakazato, \& Shiraishi, 1975). Reanalyses of earlier data sets by Digman and Takemoto-Chock (1981) and the meticulous analyses of Goldberg $(1981,1982)$ revived interest in the lexical approach and reintroduced the FFM to the mainstream of personality psychology.

There are several good reasons for beginning the search for personality dimensions in the natural language. For the layperson, personality is defined by such terms as friendly, high-strung, and punctual. These terms are the basic ways in which individuals understand themselves and others, akin to the folk concepts of Gough (1987). A complete theory of personality must ultimately explain the phenomena to which these terms refer and the ways in which they are used in everyday life. And because psychologists must often rely on self-reports and peer ratings to gather their data, they must speak the language of their informants.

But there is one more compelling reason for studying trait language. Allport and Odbert noted some 4,500 trait terms in English; surely such a wealth of vocabulary testifies to the social importance of personality traits. Conversely, if traits are so important, it seems likely that they will all be represented in the language. The lexical hypothesis holds that all important individual differences will have been noted by speakers of a natural language at some point in the evolution of the language and encoded in trait terms; by decoding these terms, we can discover the basic dimensions of personality. To the extent that the lexical hypothesis is correct, analyses of language will provide a comprehensive taxonomy of personality traits.

If we assume that personality structure is universal, we should be able 
to extract the same basic factors from analyses of any natural language, and there is some evidence to support this position. When Norman's rating scales are translated into German (Borkenau \& Ostendorf, 1990), Japanese (Bond et al., 1975), or Chinese (Yang \& Bond, 1990), similar factor structures are found. This replication is not quite the same as a rediscovery (cf. Briggs, 1989), however, because different factors might emerge if researchers began the process at the level of the dictionary: Different languages might encode a sixth factor not represented in the Norman scales. Five personality factors are found in Chinese, but they do not show a one-to-one correspondence to those found in English (Yang \& Bond, 1990); by contrast, an exhaustive study of German adjectives provides a near-perfect replication of English-language studies (Ostendorf, 1990). Similarly, analyses of personality nouns or verbs might reveal factors not found in trait adjectives. These are among the questions that concern the current generation of lexical researchers (Hofstee \& Van Heck, 1990).

\section{Personality questionnaires}

In the history of personality research, the lexical tradition has played a very small role. Most personality assessment has been based on questionnaires with scales designed for specific practical applications or to measure constructs derived from personality theory (Goldberg, 1971). Psychiatric nosology and the theories of Jung (1923/1971), Murray (1938), and Sullivan (1953), among others, have spawned a variety of instruments. Individual researchers have also created scales by the hundreds to measure more discrete constructs they deemed important (e.g., Tellegen \& Waller, in press).

Theories of personality have been remarkably diverse, and it might have been anticipated that the questionnaire scales designed to operationalize them would show little resemblance to each other. In fact, however, there is considerable redundancy in what they measure. In particular, many scales measure the chronic negative emotions that are of such great concern to psychiatrists and clinical psychologists, and many others deal with the interpersonal activity so important for social psychologists. H. J. Eysenck institutionalized these two dimensions as $\mathrm{N}$ and $\mathrm{E}$, and provided useful measures (H. J. Eysenck \& S. B. G. Eysenck, 1964, 1975); years of research convinced many psychologists that these two factors were indeed central dimensions of personality, to be found in a wide variety of instruments. 
But it also became clear that these two dimensions did not exhaust the full range of personality characteristics. In 1974, Tellegen and Atkinson proposed that there was a third broad domain of traits, all related to each other and all independent of $\mathrm{N}$ and $\mathrm{E}$; they called this "Openness to Absorbing and Self-Altering Experience," or Absorption. Independently, Costa and McCrae (1976) proposed a similar dimension of Openness to Experience. Both sets of researchers admired H. J. Eysenck's strategy of looking for broad themes by which to organize groups of traits, and sought to extend it to new dimensions. By explaining as much as possible in terms of established factors, and then looking for commonalities in what remained unexplained, researchers could proceed to a systematic mapping of personality traits.

It was at this point that the lexical and questionnaire traditions merged, leading to the contemporary FFM (Digman, 1979; Hogan, 1983; McCrae \& Costa, 1985c). Would the model have been discovered eventually without the guidance of the lexical tradition? Perhaps. As early as 1980, Costa and McCrae suggested that a dimension of selfcontrol might be needed, and Tellegen (1982) proposed a similar dimension of constraint. These are now recognizable as forms of Conscientiousness. The remaining factor-Agreeableness - might have been discovered in analyses of the Interpersonal Circumplex (Leary, 1957), which combines the dimensions of $\mathrm{E}$ and $\mathrm{A}$, or of the Myers-Briggs Type Indicator (MBTI; Myers \& McCaulley, 1985), which measures E, $\mathrm{A}, \mathrm{C}$, and $\mathrm{O}$ (see Table 2). In retrospect, at least, it is easy to imagine alternate lines of research that would have led to the FFM.

But until recently, only a small minority of questionnaire researchers were concerned with the issue of consensus-most preferred to generate new scales rather than organize those already available. One reason for this may have been the theoretical differences that divided personality researchers; another may have been the apparent hopelessness of any empirical attempt to identify basic dimensions. There were, after all, hundreds of personality inventories and scales, all requiring considerable time to complete. A grand factor analysis of all these would require thousands of subjects willing to donate days of their time, and even then there was no compelling reason to believe that the results would tell us any more than what kinds of traits trait psychologists were most interested in measuring. By contrast, lexical researchers could identify a few hundred adjectives with some confidence that they represented the full range of trait terms needed in ordinary social interaction, and subjects could rate themselves or others on these adjectives in a 
matter of minutes (Goldberg, 1989). Lexical studies were thus ideally suited for the exploration of personality structure; the model they led to could then be confirmed, enlarged, or qualified by studies of questionnaires.

Perhaps the most important contribution of the questionnaire tradition to the development of the FFM was theoretical. The lexical approach was limited to an analysis of personality traits represented in ordinary language; it might have overlooked characteristics of theoretical interest to personality psychologists. The only way to resolve this question was by comparing instruments specifically designed to measure the psychological constructs of personality theories with measures of the five lexical factors. If questionnaire measures of Murray's needs, Jung's functions, and Gough's folk concepts had not already existed, it would have been necessary to invent them.

\section{The Empirical Status of the Model}

\section{Evidence of comprehensiveness}

Until recently there were few empirical demonstrations of correspondence between lexical factors and the traits measured by personality questionnaires. Cattell's own instrument, the Sixteen Personality Factor Questionnaire (16PF; Cattell, Eber, \& Tatsuoka, 1970), was designed to parallel factors found in lexical rating studies, but it was based on a 12-factor solution that was never adequately replicated, to which Cattell added four factors he had found only in questionnaire items (John, 1990a; John et al., 1988). Norman (1969) provided early evidence that self-report questionnaires could measure the five factors, but did not subsequently pursue this approach. In the 1980 s, however, studies began to appear that used both questionnaires and trait adjectives, both self-reports and observer ratings. Amelang and Borkenau (1982) collected both self-reports and peer ratings on a set of German adjective trait rating scales, and self-reports on a diverse set of personality inventories. Five factors were found in each data set which showed some similarities to the standard five. McCrae and Costa (1985c, 1987) showed convergence for all five factors across both observers and instruments when they examined adjective scales and questionnaire measures in an adult sample on whom peer ratings on parallel instruments were available. Similar findings have been reported by Goldberg (1989), Ostendorf (1990), and Trapnell and Wiggins (1990). These studies 
demonstrate that the correspondences between similarly named factors in the two traditions are empirically justified.

Much subsequent research has relied primarily on questionnaire measures of the five factors (see Briggs, this issue, for a discussion of assessment issues). The Hogan Personality Inventory (HPI; Hogan, 1986) is based in part on the FFM, and the NEO Personality Inventory (NEOPI; Costa \& McCrae, 1985, 1989; Costa, McCrae, \& Dye, 1991) explicitly attempts to measure all five factors, as well as some of the specific traits that define the factors (see Table 1). A series of studies using the NEO-PI (Costa \& McCrae, 1988; McCrae, 1989; McCrae \& Costa, 1985a, 1989a, 1989c) examined the comprehensiveness of the model by joint analyses with alternative personality systems, including the $\mathrm{H}$. J. Eysenck and S. B. G. Eysenck (1975) scales, the Guilford-Zimmerman Temperament Survey (J. S. Guilford, Zimmerman, \& J. P. Guilford, 1976), the MBTI, Gough's (1987) revised CPI, Jackson's (1984) Personality Research Form (PRF), and Wiggins's (1979) measure of the Interpersonal Circumplex. Wiggins and Pincus (1989) explained personality disorder scales in terms of the five factors, and Noller et al. (1987; see also Boyle, 1989) found similar factors in a joint analysis of instruments developed by Eysenck, Cattell, and Comrey. Most of the scales in these instruments appeared to reflect one or more of the five factors.

Of particular interest was a study of the California Q-Set (CQS; J. Block, 1961). The CQS consists of 100 statements developed by J. Block and refined over a period of years by a large panel of dynamically oriented psychologists and psychiatrists to provide a fully comprehensive description of personality. In a sense, it may be seen as a deliberate and scientifically guided alternative to the catalog of traits spontaneously evolved in natural language. When five factors were extracted from 403 self Q-sorts, they showed a striking resemblance to the lexical factors (McCrae, Costa, \& Busch, 1986; see Table 1), and convergent correlations between these factors and NEO-PI factors ranged from .46 to .71 (McCrae \& Costa, 1989b). John (1989a) has reported similar findings using Q-sorts aggregated across five expert observers.

In addition to the empirical evidence for the model, there is something intuitively appealing about the factors: They make a great deal of sense. In part, this may be because they make explicit the implicit personality theory that is encoded in the personality language we all use; in part, the model probably squares well with our experience of self and others. In any case, it raises the question of why it took personality 
psychologists so long to recognize what in retrospect seems so obvious. There are probably a large number of reasons: an overemphasis on clinical phenomena, with excessive attention to distinctions within the domain of $\mathrm{N}$ and relative inattention to other domains; the technical difficulties of factor analysis in the early days of computers; an unproductive preoccupation with response sets; a discipline that encouraged innovation and the proliferation of scales over replication and the consolidation of findings; incorrect assumptions about measurement (e.g., assuming that ratings of intelligence were equivalent to intelligence tests); the frequently poor quality of research-what J. Block (1977) called the personality "litter-ature."

But part of the problem lies in the nature of personality structure itself. Factor analysis seeks simple structure--discrete clusters of variables that define a dimension. We now know that many of the traits of central importance to personality theory are blends of two or more of the five dimensions (Goldberg, 1989; John, 1989b). Measures of shyness, for example, typically combine elements of $\mathrm{N}$ and low $\mathrm{E}$ (Briggs, 1988). Adjectives such as hostile and temperamental may refer to attributes of high $\mathrm{N}$ or low $\mathrm{A}$. Even when all five dimensions are represented in a factor analysis, a different selection of variables can lead to a different set of dimensions within the same factor space. From a statistical point of view, this is merely a problem of rotation; all solutions are mathematically equivalent. For researchers trying to grasp the shape of personality structure, however, it proved a formidable obstacle. After all, the Copernican revolution in astronomy was "merely" a shift in the basic point of reference from the earth to the sun!

\section{Objections and responses}

The FFM is not a complete theory of personality-some would argue that it is not a theory of personality at all - and McAdams (this issue) discusses some of the limitations of the model from the broader perspective of personality psychology. In this section we would like to address some more specific objections to the model that have been cited by trait psychologists.

Too few factors. Many writers have argued that five factors are insufficient to summarize all that we know about individual differences in personality. Mershon and Gorsuch (1988) argued that stronger predictions can be made from the individual scales of the $16 \mathrm{PF}$ than from the 
higher order factors they form, and J. Block (e.g., 1971) prefers analyses of individual Q-sort items, because findings at the item level can provide a more psychologically differentiated understanding than can analyses of Q-sort factors.

Advocates of the FFM would not dispute these contentions. The five factors do not exhaust the description of personality, they merely represent the highest hierarchical level of trait description. As McCrae et al. (1986) noted, measurement of the five factors

gives a complete characterization of the person only at a global level. The factors represent groups of traits that covary, but are not necessarily interchangeable. A moderate score in Extraversion, for example, might be obtained by an individual who was energetic but aloof, or lethargic but friendly, or average on both energy level and sociability. For many purposes, these distinctions are essential. (p. 444)

In the language of factor analysis, both the common and the specific variances are useful in understanding personality.

More serious is the question of whether there are additional common factors not included among the Big Five. This is, of course, possible, though it appears increasingly unlikely, given the wealth of data in support of the comprehensiveness of the FFM. What would a Big Six factor be? A narrow Culture factor was occasionally noted in Digman and Takemoto-Chock's (1981) analyses. A Values factor (honest, moral) appears in the structure of the perceived relations among traits, but not in studies of actual people (Peabody \& Goldberg, 1989). Masculinity/ Femininity has been proposed as a major factor of personality (Kamp \& Gough, 1986), but this construct seems to be a syndrome of several independent characteristics related to different factors rather than an internally consistent dimension of personality.

Tellegen and Waller (in press) summarized an unpublished study in which substantive trait adjectives, state adjectives, and evaluative terms were all included; they found a seven-factor structure, with a Positive Evaluation (outstanding vs. ordinary) and a Negative Evaluation (awful vs. decent) factor in addition to the familiar five. Are these new factors methodological artifacts (e.g., infrequency factors)? Are they aspects of the self-concept that can be subsumed by the existing factors? Low self-esteem is known to be a correlate of $\mathrm{N}$ (Costa et al., 1991), and narcissistic self-regard is related to $\mathrm{E}$ and low $\mathrm{A}$. It seems unlikely that these two factors represent substantive aspects of personality that could 
be consensually validated. To what specific behaviors could one point that would confirm that an individual was awful or outstanding?

As critics of the FFM have pointed out, it frequently happens that analyses of specific personality instruments show evidence of more than five factors (Lanning \& Gough, 1991), but this is probably due to method artifacts, sampling variability, or the particular selection of variables and does not in itself demonstrate the need for additional common factors in personality description. For example, when Piedmont, McCrae, and Costa (1991) jointly factored NEO-PI factors and the scales of Gough and Heilbrun's ACL, they found six eigenvalues greater than 1.0. The first five factors represented $\mathrm{C}, \mathrm{A}, \mathrm{E}, \mathrm{N}$, and $\mathrm{O}$, respectively; the sixth factor was a doublet contrasting ACL Communality with Welsh's A-1 (high origence, low intellectance) scale. The interpretation of this sixth factor is unclear, but whatever it measures, it seems to be unique to this analysis, not a robust factor found in many instruments. So far, no proposed sixth factor has stood this test. Lexical studies in particular have shown that factors beyond the fifth are not replicable (Goldberg, 1990; Ostendorf, 1990).

One major qualification of that generalization is needed. When factored jointly with personality variables, measures of cognitive ability typically form a distinct sixth factor (Krug \& Johns, 1986; McCrae \& Costa, 1985b, 1985c). Some psychologists (e.g., Brand, 1984) regard intelligence as part of the personality sphere; if it is to be included, it should be recognized as a distinct factor, long familiar as $g$. Confusions between $g$ and $\mathrm{O}$ are discussed in a later section.

Too many factors. Some researchers do not feel that all five factors are needed. Zuckerman et al. (1988) argued that three factors, corresponding to H. J. Eysenck's E, N, and P (or Psychoticism, a dimension related to low $\mathrm{A}$ and low $\mathrm{C}$ ), account for the bulk of variance. Cloninger (1988), Gough (1987), and Tellegen (1982) also have three-factor theories. Peabody (1987) noted that $\mathrm{N}$-related trait terms are relatively rare in English, and thus that the inclusion of a separate emotional stability factor is not justified by analyses of trait adjectives. Digman (1985) suggested that there might be two higher order factors: Socialization (combining $\mathrm{A}$ and $\mathrm{C}$ with low $\mathrm{N}$ ) and Self-Actualization (combining $\mathrm{E}$, $\mathrm{O}$, and low N); and Hogan (in press) stated that "these five factors can be reduced to three through higher order factor analysis."

The problem with all these proposals is that they are mutually inconsistent. N, which is crucial to H. J. Eysenck's system, could be left 
out of Peabody's. Low A and low C are collapsed in H. J. Eysenck's conception of Psychoticism, whereas low A is combined with $\mathrm{N}$ to form Tellegen's Negative Emotionality. It appears that all five factors are necessary, and this observation is supported by empirical analyses. In parallel analyses, McCrae and Costa (1987) extracted factors from 80 adjective pairs in one sample of self-reports and one of peer ratings. When fewer-or more - than five factors were extracted, they could not be matched across the two samples, but an almost perfect match was found with five factors. Similar analyses, with similar results, have been reported by Borkenau and Ostendorf (1990), Goldberg (1990), and Digman (1989). Five factors, it seems, are "just right."

Ratings versus self-reports. Hogan (in press) has drawn sharp distinctions between observer ratings of personality, which are said to represent the public self or social reputation, and self-reports, which reflect inner drives and dispositions, and argued that the FFM is adequate only as a description of the former ( $R$. Hogan, personal communication, January 20, 1990; see also McAdams, this issue). This objection is somewhat puzzling in view of the repeated recovery of the five factors in self-report data. The very first report of the model was Fiske's (1949) demonstration of similar factors in peer ratings, expert ratings, and self-reports. Questionnaire measures like the NEO-PI also yield comparable factor structures for self-reports, spouse ratings, and peer ratings (McCrae \& Costa, 1989b). Agreement between sources on an individual's standing on the five dimensions is less than perfect (although it is substantial; see Funder \& Colvin, in press), but the structures of personality descriptions seem virtually identical. ${ }^{3}$

Tellegen and Waller (in press) made a somewhat different distinction. They considered the Big Five to be folk concepts, useful chiefly in understanding the ways in which personality is perceived and described by laypersons. They argued that more meaningful measures may be derived from psychological concepts derived from scientific theory and research. Although relations between these two levels of analysis are expectable (and are in fact reported by Tellegen and Waller), folk

3. McAdams (this issue) also distinguishes between experienced and observed personality, pointing out that questionnaires and rating scales require the individual to describe himself or herself from the perspective of an observer. This is appropriate, he argues. only for the most superficial understanding of the individual; a fuller picture requires contextualized and nuanced attributions that are not found in trait descriptions. But see Funder (1991) for a defense of global trait constructs. 
and psychological concepts are not isomorphic. In particular, Tellegen (personal communication, February 24, 1990) has suggested that the structure of scales derived from psychological concepts may be different in self-report and rating data. This is a possibility that merits further research, but it does not seem to pose any direct challenge to the crossobserver invariance of the FFM itself. Note also that the recovery of the five factors does not depend on the use of lay raters: When clinical and personality psychologists use adjectives or Q-sorts to describe individuals, the same structure is found (John, 1989a, 1990a).

Cognitive artifacts versus realistic description. As Borkenau (this issue) describes, the five-factor model has been at the center of the controversy about the veridicality of traits. People's implicit personality theories, as revealed through their ratings of strangers and judgments of similarity in trait terms, appear to be structured by dimensions that closely resemble the FFM. This raises the possibility that the FFM is itself nothing more than a projection of our cognitive biases onto the targets we rate. A variety of ingenious studies have been devised to test this hypothesis, and although it still has some proponents, most personality psychologists have rejected it.

Borkenau reviews several lines of evidence that point to the veridicality of traits and trait factors; two others can be briefly noted. First, at least one version of the cognitive bias theory holds that the fivefactor structure is embedded in the language of personality description: Warm and gregarious may define the same factor not because these two traits covary in people, but because the words themselves are quasi-synonyms, referring in part to the same interpersonal behaviors; Borkenau (this issue) call this "referential overlap" between the two constructs. In a sense this is true: Peabody's (1987) studies of the internal (i.e., definitional) structure of traits reveal something resembling the five-factor model. The radical interpretation of this phenomenon is that the structure of traits is an arbitrary artifact of language: With a different set of personality terms, we would find a different set of factors. But cross-cultural research to date has instead found very similar factors in widely different languages. It is surely more parsimonious to believe that human languages have evolved to reflect human nature than to suppose that the same fiction has been recreated independently in many different cultures.

Second, it is difficult to understand how cognitive fictions can explain real-life outcomes. Yet the five factors have been shown to predict exter- 
nal criteria from divergent thinking abilities (McCrae, 1987) to marital adjustment and divorce (Kelly \& Conley, 1987), to coronary disease endpoints (Dembroski, MacDougall, Costa, \& Grandits, 1989), to job performance criteria (Barrick \& Mount, 1991). These applications of the FFM provide some of the most impressive evidence of its validity.

A second artifactual hypothesis, raised most recently by Digman (1990), is that the number of factors is the result of cognitive limitations in information processing (Miller, 1956). Given greater cognitive complexity, we might be able to make finer distinctions in our conceptions of personality, and more factors might emerge from analyses of trait ratings. Appealing as it is, this argument does not appear to be plausible on closer inspection. Factor analyses are based on the judgments of many observers, so the cognitive limitations of individual raters would not affect the factor structure-unless all the individuals shared the same perceptual biases. Shared language might explain this shared bias, but why then would other cultures show the same structure? For that matter, if conceptual convenience is the basis for the number of factors, why not the magical number of seven factors?

If we reject the information-processing explanation of why there are five factors, what rationale remains? We believe it is simply an empirical fact, like the fact that there are seven continents on earth or eight American presidents from Virginia. Biologists recognize eight classes of vertebrates (mammals, birds, reptiles, amphibians, and four classes of fishes, one extinct), and the theory of evolution helps to explain the development of these classes. It does not, however, explain why eight classes evolved, rather than four or eleven, and no one considers this a defect in the theory. There are, of course, reasons why human beings differ along each of the five personality dimensions-reasons to be found somewhere in evolution, neurobiology, socialization, or the existential human condition. But it is probably not meaningful or profitable to ask why there happen to be just five such dimensions.

\section{Conceptualizations of the Factors: Description and Explanation}

The problem of what to call the factors is not merely a matter of convention. The labels reflect conceptualizations, and five-factor advocates differ in the details of their views on the factors, and thus in their preferred names. At one level, about which a good deal has been written, these differences are descriptive: Precisely which traits define each 
factor, and which are central, which peripheral? At another level, the differences are theoretical: Why are there universal dimensions of personality, and why these dimensions and not others? Considerably less has been said about this topic, and we hope in the present article to outline some of the possible explanations. Obviously, the two levels of conceptualization are related, because theory must be tailored to the phenomenon to be explained.

\section{Factor definitions}

There is probably the least controversy about the definition of $\mathrm{N}$. N represents individual differences in the tendency to experience distress, and in the cognitive and behavioral styles that follow from this tendency. High $\mathrm{N}$ scorers experience chronic negative affects (Watson \& Clark, 1984) and are prone to the development of a variety of psychiatric disorders (Zonderman, Stone, \& Costa, 1989). The recurrent nervous tension, depression, frustration, guilt, and self-consciousness that such individuals feel is often associated with irrational thinking, low self-esteem, poor control of impulses and cravings, somatic complaints, and ineffective coping (McCrae \& Costa, 1987). Individuals low in $\mathrm{N}$ are not necessarily high in positive mental health, however that may be defined-they are simply calm, relaxed, even-tempered, unflappable.

Despite the long and common use of the term Extraversion, there is less consensus about $\mathrm{E}$. Most of the differences can be traced to the fact that $E$ and $A$ together define the Interpersonal Circumplex, around which interpersonal terms are spaced almost evenly. The traditional axes of the circumplex are Dominance (or Status) and Affiliation (or Love; Wiggins, 1979), and the major dispute about E (Norman's Factor I) concerns its alignment with these axes. Goldberg (1990), guided by his analyses of English language trait terms, and Wiggins (in press), guided by the interpersonal tradition, identify this factor with Dominance. McCrae and Costa $(1989 \mathrm{c})$ argue that $E$ is best seen as located midway between Dominance and Warmth (although perhaps a bit closer to Dominance). This position, which Peabody and Goldberg (1989) designate as $\mathrm{I}^{\prime}$, is close to the location of such traditional questionnaire measures of E as H. J. Eysenck and S. B. G. Eysenck's (1975) E scale and the EI scale of the MBTI.

The advantage of the I' position is that it aligns the factor more closely with its noninterpersonal aspects, particularly positive emotionality. As 
Watson and Clark describe in their contribution to this issue, the tendencies to experience positive and negative emotions are not opposites, but orthogonal dimensions that define an affective plane. People who are cheerful, enthusiastic, optimistic, and energetic are not necessarily low in anxiety or depression - that depends on their level of $\mathrm{N}$. But cheerful people consistently tend to be dominant, talkative, sociable, and warm, and Watson and Clark (in press) argue that positive emotionality should be seen as the core of $\mathrm{E}$. This somewhat unorthodox view is probably a useful corrective to the narrowly interpersonal interpretation of $E$ as sociability.

$E$ is distinguished by its breadth of content. In their review, Watson and Clark (in press) identified seven components of E: venturesomeness, affiliation, positive affectivity, energy, ascendance, and ambition. As Table 1 shows, Costa and McCrae's view of $E$ is similarly broad, although they would divide affiliation into warmth and gregariousness and assign ambition to $\mathrm{C}$. ${ }^{4}$ The fact that such a wide variety of interpersonal, affective, and temperamental variables covary probably accounts for the fact that this factor is so well represented in English language adjectives and so often described by personality theorists.

The lexical literature suggests that individuals low in $\mathrm{E}$ can be described as quiet, reserved, retiring, shy, silent, and withdrawn (John, 1990a), and Q-sort correlates point to emotional blandness and overcontrol of impulses as additional attributes. Nowhere in this description is introspectiveness seen: Low E must be distinguished from Guilford's (1977) Thinking Introversion (which is more closely related to $O$ and C). The confusion between social and thinking introversions is perpetuated in the MBTI, where both kinds of traits are attributed to individuals classified as Introverts. In fact, the MBTI EI scale is a relatively pure measure of low E (McCrae \& Costa, 1989a).

The label Agreeableness has been almost universally used for Norman's Factor II, but as Digman (1990) noted, "Agreeableness . . . seems tepid for a dimension that appears to involve the more humane aspects of humanity - characteristics such as altruism, nurturance, caring, and emotional support at the one end of the dimension, and hos-

4. Two sets of distinctions need to be made here. Warmth, interpreted as heartiness and affection, is more closely related to $\mathrm{E}$ than to $\mathrm{A}$; interpreted as compassion and sympathy, it is more closely related to A than E. Similarly, the term ambitious may mean wanting to get ahead, or wanting to get things done. The former is probably an aspect of $E$, the latter an aspect of $C$. 
tility, indifference to others, self-centeredness, spitefulness, and jealousy at the other" (pp. 422-424). Digman and Takemoto-Chock (1981) offered "Friendly Compliance versus Hostile Noncompliance" as an alternative descriptor for the factor, and Graziano and Eisenberg (in press) adopted the contrast "Agreeableness versus Antagonism."

Because A must be orthogonal to $\mathrm{E}$, the location-and thus the interpretation-of A depends to some extent on one's view of E. Again, Goldberg and Wiggins see this factor as Love or Warmth; Costa et al. (1991) note a cluster of attributes that blend Warmth and Submission, including trust, modesty, and compliance.

Like A, C is a highly evaluated dimension; indeed, $\mathrm{A}$ and $\mathrm{C}$ are the classic dimensions of character, describing "good" versus "evil" and "strong-willed" versus "weak-willed" individuals. Perhaps it was these moral overtones that often led scientific psychologists to ignore these factors, but in fact, both represent objectively observable dimensions of individual differences. Some people are thorough, neat, wellorganized, diligent, and achievement-oriented, whereas others are not, and self-reports of these characteristics can be validated by peer or spouse ratings (McCrae \& Costa, 1987).

A number of different conceptions of $\mathrm{C}$ have been offered. Tellegen's (1982) Constraint and Hogan's (1986) Prudence reflect an inhibitive view of $\mathrm{C}$ as a dimension that holds impulsive behavior in check. Digman and Takemoto-Chock's (1981) Will to Achieve represents a proactive view of $\mathrm{C}$ as a dimension that organizes and directs behavior. The term Conscientiousness combines both aspects, because it can mean either governed by conscience or diligent and thorough. Empirically, both kinds of traits seem to covary.

The greatest controversy concerns $\mathrm{O}$, and the root of the controversy is the disparity between natural language and questionnaire studies. Studies of trait adjectives in English (Goldberg, 1990; John, 1990a) and German (Ostendorf, 1990) typically show a factor defined by such items as intelligent, imaginative, and perceptive, and researchers from Fiske (1949) to Hogan (1986) and Digman (1990) have identified this factor as some form of Intellect. However, many traits related to $\mathrm{O}$ are not represented among English trait adjectives-there is, for example, no single English word that means "sensitive to art and beauty" (McCrae, 1990). Researchers using questionnaires have typically found a much broader factor that includes, in addition to creativity and intellectual interests, differentiated emotions, aesthetic sensitivity, need for variety, and unconventional values. This broader concept can be traced 
to Rogers (1961), Rokeach (1960), and Coan (1974); McCrae and Costa (in press) have argued that $\mathrm{O}$ is seen structurally in the depth, scope, and permeability of consciousness, and motivationally in the need for variety and experience. Ideas, of course, form an important aspect of consciousness, but fantasies, feelings, sensations, and values are also experiences to which individuals can be more or less open.

Several discussions of the relative merits of these two conceptions have been offered (Digman, 1990; John, 1990a; McCrae \& Costa, 1985b, in press; Peabody \& Goldberg, 1989). One point that should be emphasized is that neither Openness nor Intellect is equivalent to measured intelligence; $\mathrm{O}$ is a dimension of personality, not intellectual ability, and many people score high in $\mathrm{O}$ without having a correspondingly high IQ.

A recent study illustrates the empirical basis for broadening the conception of this factor beyond Intellect. John (1989a) examined ACL and CQS data from expert raters at the Institute of Personality Assessment and Research. Based on a review of the literature, a panel of judges selected 112 prototype items from the ACL to mark the five dimensions. Many of the terms selected to represent $O$ were consistent with either an Intellect or an Openness interpretation, including wide interests, imaginative, original, curious, and artistic. But because the literature emphasized the Intellect interpretation, judges also included such terms as wise, logical, and foresighted. When observer ratings on the 112 items were factored for a sample of 280 ratees, the five-factor model was clearly recovered, but wise, logical, and foresighted were not among the clear definers of the Intellect/Openness factor (Table 1 lists the six highest-loading adjectives). Empirical analyses shifted the factor from a clear Intellect to a mixed Intellect/Openness factor.

When ACL factor scores were correlated with CQS ratings by the same experts, the significant correlates $(|r|>.40)$ showed the full range of traits associated with Openness. Individuals rated low on the factor were described by "judges in conventional terms," "favors conservative values," and "represses anxiety;" those rated high were described by "high degree of intellectual capacity," "enjoys aesthetic impressions," "has wide interests," and "unusual, unconventional thought." As seen in this list, $\mathrm{O}$ includes aspects of intellect, but is considerably broader in scope. 


\section{Toward a theoretical basis of the five factors}

Personality psychologists have a particularly strong allegiance to theory - what other field of psychology uses a historical review of theories as the standard undergraduate introduction to its subject matter?--and research not grounded in recognized theory is often deprecated as "dustbowl empiricism" (cf. Little, 1989, Footnote 6). Although the fivefactor model is undeniably an empirical generalization, we will argue that it is not mindless empiricism. In one sense, the model is transtheoretical; in another, it provides one of the most important phenomena for personality theorists to explain.

A complete theory of personality should address universal personality processes, common dimensions of individual differences, and unique characteristics of the individual (cf. Kluckhohn \& Murray, 1953). The FFM is clearly most relevant to the second of these three issues, but it should be pointed out that it also has implications for the first. Although individuals differ on their standing on the five factors, the factors themselves point to universal issues. All people must be responsive to danger, loss, and threat; interact with others to some degree; choose between the risks of exploration and the limitations of familiarity; weigh self- against social interest; balance work and play. Personality processes, by definition, involve some change in the thoughts, feelings, and actions of an individual; all these intra-individual changes seem to be mirrored by interindividual differences in characteristic ways of thinking, feeling, and acting-differences that are summarized, at the broadest level, by the five factors.

The FFM is a version of trait theory, a view of the world that sees the essence of human nature in individual differences. Trait theory has been the dominant paradigm in European personality psychology (Thomae, 1989), and has been a major element of American psychology at least since Allport's time (A. H. Buss, 1989). The assumptions of trait theory are implicit in much of psychometrics, and in this form are adopted by many researchers who would not identify themselves as trait theorists. The fact that we typically require internal consistency and retest reliability from scales makes sense only because we expect to find consistent and enduring individual differences - the cardinal features of traits.

The lexical tradition is based on a specific set of theoretical assumptions: that traits can be inferred with reasonable accuracy by laypersons on the basis of daily experience, that they are of sufficient social signifi- 
cance to be recognized by every culture and encoded in every language, and that individual traits covary along a fairly limited set of basic dimensions. Analysis of the natural language is not mindless empiricism, it is systematic and theoretically guided scientific observation.

At first glance, the case for mindless empiricism seems better justified with regard to the questionnaire tradition, where many scales were created with precious little rationale. But some important questionnaires were created to operationalize specific theories of personality. The MBTI is an attempt to measure Jungian functions and attitudes; the PRF was designed to assess Murray's needs; the Millon Clinical Multiaxial Inventory operationalizes Millon's (1983) theory of personality disorders; H. J. Eysenck's EPQ and Cloninger's (1988) Tridimensional Personality Questionnaire (TPQ) scales are associated with neurophysiological theories of personality. Yet, at a broad level of abstraction, the five factors capture the commonalities among the scales in all these instruments.

It may seem puzzling that similar factors are found whether one begins from Cloninger's neuroadaptive model or Murray's motivational analysis or Jung's modes of encountering the world, but the puzzle is easily explained. All personality theorists are trying to explain some aspect of human nature; all see the same regularities, and frame theories to explain them. To the extent that the FFM summarizes fundamental regularities in human behavior, redundancy among these measures is inevitable. There is also a somewhat more subtle reason for convergence: Scales like those in the MBTI, TPQ, and PRF were developed with the help of psychometrically guided item analyses. Theorists might specify an array of heterogeneous characteristics unrelated to any of the five factors, but item analyses would tend to purify the scale in the direction of one or more of the factors. Jung's theoretical descriptions are often vague and seemingly contradictory, but the scales of the MBTI are clearly related to four of the five basic factors (McCrae \& Costa, 1989a).

We would not argue that the FFM obviates theories of personality. Personality theories have much to do beyond explaining individual differences, as McAdams notes in this issue. But we do believe that the five factors are much more than statistical artifacts ground out by computers. These are basic dimensions of personality that, in one guise or another, have been pointed out by many of the most perceptive personality theorists. 


\section{An agenda for theorizing}

If the history of research on personality theories teaches anything, it is that many quite different approaches lead back to the common dimensions described by the FFM. It is therefore unlikely that any single theory will be sufficient to account for the model; instead, different theories can usefully address different aspects of the model at different levels of explanation. These different theories are likely to be complementary, rather than mutually exclusive (Hyland, 1985). Our goal here is to articulate some of the problems that can be addressed and comment briefly on the current status of different approaches.

Perhaps the most basic theoretical issue is the nature of traits themselves. Recent treatments of the topic are offered by Funder (1991), Read, Jones, and Miller (1990), Tellegen (in press), and Wiggins and Trapnell (in press). One useful way to define traits is extensional: Traits are the sorts of attributes listed in Table 1 . Working inductively from our empirical knowledge of these traits, we could develop an intensional definition. Do traits have motivational properties? Talkative people want to talk, sympathetic people want to help; ergo, at least some traits have motivational properties. Are traits enduring dispositions? There is longitudinal evidence of stability for traits from all five factors (McCrae \& Costa, 1990), so traits are indeed enduring dispositions. A series of exemplars and a body of facts about them is not a substitute for clear conceptualization, but they can ground different attempts at definition in a shared specification of the phenomenon to be defined.

What is to be explained? Different theories may address different issues related to the FFM. The lexical tradition has focused on the codification of lay perceptions of personality, and it would be of interest to develop sociohistorical theories of the evolution of personality language (Benjafield \& Carson, 1985; Goldberg, 1981). Cognitive theorists could address the development of implicit personality theories in the child, and social psychologists could offer explanations for social perceptionhow we match up internalized constructs with actual individuals we meet (Kenny, 1991). Clinicians might be particularly concerned with processes that lead to distortions in self-image, and psychometricians can address item response theory and self-presentation. In each case, the five factors specify the universe of content which these theories must address.

Although Hogan (in press) prefers to view the traits that define the 
five factors as matters chiefly of social perception and reputation, we adopt the view that traits are real entities (cf. Funder, 1991), and we will focus here on explanations for the factors themselves as traits possessed by individuals. Why are there individual differences in traits? Why do the traits covary to form factors? Why these factors and not others? What is their origin in the species and in the individual? What is their neurophysiological basis, their course of development, their functional significance?

In pursuing all these questions, theorists would do well to consider the relation between the factors and the traits that define them. Cattell (1946) viewed primary traits as the more meaningful level of analysis, whereas H. J. Eysenck's (1967) theories addressed the superordinate dimensions of $\mathrm{E}$ and $\mathrm{N}$. Watson and Clark (in press) have suggested that one aspect of E, Positive Emotionality, is the core element, which motivates other elements such as sociability and activity; the factor expresses this functional unity. Alternatively, it could be argued that individuals inherit a set of general predispositions associated with the five factors, and that environmental conditions determine the particular forms - the specific traits-in which the factors are expressed.

Psychophysiological theories. Trait psychologists from Allport (1937) on have assumed that the experiential and behavioral regularities that we identify as traits have some physiological substrate. H. J. Eysenck's prominent status as a personality theorist can be attributed in large part to his sustained efforts to develop a physiological theory of $\mathrm{E}$ and $\mathrm{N}$ (and later Psychoticism; H. J. Eysenck \& S. B. G. Eysenck, 1976). More recently, Cloninger (1988) has offered a biosocial theory of personality based on chemically coded neural networks, and Zuckerman (1984) has used comparative psychophysiology to explain sensation seeking, a trait related to $\mathrm{O}$ (McCrae \& Costa, in press).

The possibility of psychopharmacological interventions makes such theories of more than academic significance. At present, however, none of them has been entirely persuasive. Compared to the intricacies of the brain, our knowledge of neurophysiology and functioning is still quite primitive, and none of the key theorists in this field has even offered an explanation for all five factors. The complexities are enormous. For example, Depue, Krauss, and Spoont (1987; cited in Watson and Clark, in press) drew parallels between bipolar mood disorders and individual differences in E: In manic phases, bipolar patients show all the characteristic traits of extraverts, whereas during depressive episodes they 
are functionally introverted. As a trait, however, depression is not associated with introversion, but with $\mathbf{N}$. It is difficult to understand how the same brain mechanism can lead to one bipolar dimension of mania versus depression within individuals and to two orthogonal factors of $\mathrm{E}$ and $\mathrm{N}$ across individuals. Theorists have much work to do here.

Evolutionary perspectives and behavior genetics. In recent years, evolutionary biologists have begun to offer explanations for behavior, and personality psychologists have become interested in evolutionary arguments (D. M. Buss, 1990; Hogan, 1983). Facile assertions that the five factors exist because they contribute to survival and reproduction are not very useful scientifically, and contemporary theorists are keenly aware of the difficulties in making supportable evolutionary arguments. The central problem is that classic evolutionary theory was designed to explain the origin of species; it focuses on interspecies differences, not individual differences within a species. In this respect, evolutionary psychology is better equipped to tell us how individuals are like all other people than how they are like only some other people (Kluckhohn \& Murray, 1953).

Some evolutionary models for individual differences have been proposed; for example, if the adaptive value of characteristics has fluctuated over evolutionary time, heritable differences may have developed (D. M. Buss, 1991). It is also possible, however, that individual differences in personality are, from the viewpoint of evolution, mere "noise," of no adaptive significance- a position argued cogently by Tooby and Cosmides (1990). The apparent adaptive utility of differentiation in personality among members of contemporary cultures may be the result of cultural evolution rather than biological evolution: Because people differ in levels of personality traits, cultures may have developed social and occupational niches that capitalized on them.

Although differences in standing on the five factors may not have adaptive significance, there are adaptive advantages in being able to detect these individual differences in others: It is very useful to know who is compliant and who is aggressive, who is diligent and who is negligent. D. M. Buss (1991) argued that the five factors may represent "important dimensions of the social terrain that humans were selected to attend to and act upon" (p. 473). This would account for their representation in many cultures, and would explode the view that they are mere cognitive fictions: Natural selection would hardly favor the preservation of illusory perceptions. 
Evolutionary approaches are worthy of serious interest because there is already substantial evidence on the heritability of many traits. Research has been conducted for decades on the heritability of $\mathrm{N}$ and $\mathrm{E}$, and recent work has suggested that $\mathrm{O}$ and $\mathrm{C}$ are also substantially heritable (Plomin \& McClearn, 1990). Although Plomin and McClearn found no evidence of heritability with their 10 -item measure of A, other studies have reported a strong genetic component in measures of altruism and aggression, which are central aspects of A (Rushton, Fulker, Neale, Nias, \& H. J. Eysenck, 1986). Future studies should surely include measures of all five factors, and interesting questions about the relations of traits to factors could be addressed if component traits for all factors were individually assessed in these studies.

Developmental theories. Although personality and temperament are traditional topics in developmental psychology, they have not been well integrated with theories of adult personality. Developmental psychologists tend to be interested in the social and emotional reactions of children of a particular age, without much regard to the ultimate outcome of these characteristics in adulthood. Longitudinal research (J. Block, 1971; Caspi, Elder, \& Bem, 1987) shows some continuities in personality from childhood into adulthood, but many discontinuities as well. If we could identify at birth future extraverts and future introverts, future open and closed individuals, we could trace their development with a more informed eye; as it is, we must rely on retrospective-predictive designs that are limited by the kinds of observations initially made.

However, developmental psychologists should at least begin to consider the implications of the FFM for their theories. J. H. Block and J. Block (1980), for example, discussed the development of ego control, a variable that combines elements of low $\mathrm{E}$ and high $\mathrm{C}$. Are these dimensions indistinguishable in early childhood, necessitating a theory of their developmental differentiation? Or have theorists mistakenly conflated two independent dimensions? A child who is high in both $\mathrm{E}$ and $\mathrm{C}$ may have the same average level of ego control as one who is low on both dimensions; would both children show the same social and emotional development? Fortunately, there are now signs that this integration of developmental and adult models of personality is beginning (e.g., Angleitner \& Ostendorf, 1991).

Dynamic and interpersonal theories. Theories of the origins of personality traits tell only half the story. The other half is provided by 
theories of the operation of traits in the real world, their functional-or dysfunctional-significance. In the area of psychopathology, the task is reasonably well articulated. The disorders recognized by psychiatry constitute the topic to be explained, and the questions concern the extent to which these disorders can be understood in terms of the five personality dimensions (Widiger \& Trull, this issue). Historically, abnormal psychology has been the source of many theories of personality; it will surely offer an interesting perspective on the FFM.

Perhaps as a prelude to understanding abnormal psychology, we need theories that explain the dynamic operation of traits in normal life. We know in general how individual traits are manifested in behavior: High $\mathrm{E}$ individuals talk and smile, high $\mathrm{O}$ individuals philosophize and attend museums, low A individuals brag and bully. We know much less about how configurations of traits are shown, or how the flow of behavior is governed. Are traits expressed by turns, or through processes like subsidiation and fusion that Murray (1938) postulated for the satisfaction of needs? Little, Lecci, and Watkinson (this issue) discuss the organization of life in terms of personal projects, and provide data linking features of these projects to the five factors.

Some theorists (J. Block, 1965; Loevinger, 1966) have suggested that there are features of the ego that organize behavior; these are considered "master traits" that regulate other traits. But McCrae and Costa (1990) argued that measures of ego resiliency, ego control, and ego development level are themselves related to the five factors (and intelligence), and that each of the five factors can be regarded both as a set of traits that must be structured and organized, and as a contributor to the organization and interaction of other traits. Consider $\mathrm{O}$ and $\mathrm{C}$ : Open people are inquisitive. If they are also conscientious, their curiosity may take the form of sustained and systematic study of a topic; if they are low in $\mathrm{C}$, theirs will be an idle curiosity, absorbed by the passing interest of the moment. Theoretical elaboration of such interactions of factors can bring a more dynamic flavor to trait psychology.

Finally, much of behavior is interpersonal, and the relationships individuals evolve are likely to be a complex function of the personalities of both participants. The work of Thorne (1987) on interactions between introverts and extraverts, of Bond and Forgas (1984) on the relations between person perception and behavioral intensions, of Kelly and Conley (1987) on marital compatibility, of D. M. Buss (this issue) on tactics of manipulation, and of Mutén (1991) on spousal perceptions of personality among behavioral medicine patients all touch on this issue. A full 
theoretical account of the contributions of personality to interpersonal relationships is a monumental task; how much more daunting it would be without the simplifying guidance of the FFM!

\section{Applications of the Five-Factor Model}

Hogan (1987) has noted that the five-factor model, perhaps for the first time, gives personality psychology a replicable phenomenon to be explained. At the same time, it also provides a set of tools that can be used by psychologists in many different areas. Several new instruments have been published which provide operationalizations of the model (see Briggs, this issue, for a review), and both rational and empirical methods for interpreting existing instruments in this framework have been proposed (John, 1989b; McCrae, Piedmont, \& Costa, 1990).

The appeal of the model is threefold: It integrates a wide array of personality constructs, thus facilitating communication among researchers of many different orientations; it is comprehensive, giving a basis for systematic exploration of the relations between personality and other phenomena; and it is efficient, providing at least a global description of personality with as few as five scores. Of these, comprehensiveness is perhaps the most crucial. Without a comprehensive model, studies using personality traits as predictors are inconclusive, because the most relevant traits may have been overlooked. This is unlikely to happen when measures of all five factors are included in a study. Indeed, even null results are informative in such a study: If none of the factors is related to the criterion, it may be time to abandon the search for personality predictors.

The five-factor model can be profitably used in most applied settings, as Tupes and Christal (1961) noted long ago, and as other practitioners are beginning to realize. Hogan (in press) discusses the relevance of personality for industrial and organizational psychology. Costa (1991) presents a series of articles exploring the utility of the model for clinical psychologists, and McCrae and Costa (1991) discuss its application in counseling. Educational, forensic, and health psychologists should be able to find ways to utilize the model in their own disciplines. Indeed, anywhere personality assessment has been employed may benefit from a consideration of the five-factor model.

Most of the articles in this special issue apply the model at a more conceptual level, not to understand individuals, but to clarify issues in disciplines related to personality psychology. Widiger and Trull exam- 
ine both personality disorders and some Axis I psychopathology from the perspective of the model. Smith and Williams argue that the model, and the tradition of construct validity from which it has emerged, can resolve some of the confusion among the many, often redundant, concepts used in health psychology. Graziano and Ward show how the five-factor model can illuminate school adjustment. Watson and Clark continue to elaborate a model linking personality traits to emotions, and D. M. Buss uses the model to understand interpersonal relations from the perspective of evolutionary personality psychology. Finally, Little, Lecci, and Watkinson explore the ways in which enduring personality dispositions affect the personal projects that occupy individuals in their daily lives. This approach promises to help integrate nomothetic and idiographic approaches to personality, and shows some of the ways in which the FFM is relevant to an understanding of the ways in which individuals are unique.

All of these authors have found the five-factor model useful in some way; they have also noted ways in which it is limited. As McAdams argues, personality psychology has historically been concerned with much more than common dimensions of individual difference, and the five-factor model itself cannot hope to account for all the richness of human individuality, or all the processes that contribute to a coherent life structure and an evolving life history. But neither is it irrelevant to a personality psychology that strives to understand the whole person. Every extravert may be extraverted in his or her own way, yet all are extraverts. History, culture, and development provide the context of individual lives, but so do enduring dispositions (McCrae \& Costa, 1990).

We believe its long history, cross-cultural replication, and empirical validation across many methods and instruments make the five-factor model a basic discovery of personality psychology-core knowledge upon which other findings can be built. The model will certainly not explain everything that psychologists want to know about personality, but it does provide a useful starting point, and, indeed, a challenge: What can new scales, new methods, new conceptions of personality add to what we already can understand and predict from knowledge of the five factors? For the past two decades, personality psychology has worked to establish the validity of its basic constructs. For the future, the issue will be incremental validity, as personality psychology begins to become a cumulative science. 


\section{REFERENCES}

Allport, G. W. (1937). Personality: A psychological interpretation. New York: Holt. Allport, G. W., \& Odbert, H. S. (1936). Trait names: A psycho-lexical study. Psychological Monographs, 47 (1, Whole No. 211).

Amelang, M., \& Borkenau, P. (1982). Über die faktorielle Struktur und externe Validität einiger Fragebogen-Skalen zur Erfassung von Dimensionen der Extraversion und emotionalen Labilität [On the factor structure and external validity of some questionnaire scales measuring dimensions of extraversion and neuroticism]. Zeitschrift für Differentielle und Diagnostische Psychologie, 3, 119-146.

Angleitner, A., \& Ostendorf, F. (1991, June). Temperament and the Big Five factors of personality. Paper presented at the conference on the Developing Structure of Temperament and Personality in Childhood. Netherlands Institute for Advanced Studies in the Humanities and Social Sciences, Wassenaar. The Netherlands.

Barrick, M. R., \& Mount, M. K. (1991). The Big Five personality dimensions and job performance: A meta-analysis. Personnel Psychology, 44, 1-26.

Benjafield, J., \& Carson, E. (1985). An historicodevelopmental analysis of the circumplex model of trait descriptive terms. Canadian Journal of Behavioural Science. 17, 339-345.

Block, J. (1961). The Q-sort method in personality assessment and psychiatric research. Springfield, IL: Charles C Thomas.

Block, J. (1965). The challenge of response sets. New York: Appleton-Century-Crofts.

Block, J. (1971). Lives through time. Berkeley: Bancroft Books.

Block, J. (1977). The Eysencks and psychoticism. Journal of Abnormal Psychology, 86, 653-654.

Block, J. H., \& Block, J. (1980). The role of ego control and ego resiliency in the organization of behavior. In W. A. Collins (Ed.), Development of cognition, affect, and social relations: The Minnesota symposium on child psychology (Vol. 13. pp. 39-101). Hillsdale, NJ: Lawrence Erlbaum.

Bond, M. H. (1979). Dimensions of personality used in perceiving peers: Crosscultural comparisons of Hong Kong. Japanese. American. and Filipino university students. International Journal of Psychology, 14, 47-56.

Bond, M. H., \& Forgas, J. P. (1984). Linking person perception to behavior intention across cultures: The role of cultural collectivism. Journal of Cross-Cultural Psychology, 15, 337-352.

Bond, M. H., Nakazato, H., \& Shiraishi, D. (1975). Universality and distinctiveness in dimensions of Japanese person perception. Journal of Cross-Cultural Psychology. 6, 346-357.

Borkenau, P., \& Ostendorf, F. (1989). Untersuchungen zum Fünf-Factoren-Modell der Persönlichkeit und seiner diagnostischen Erfassung [Investigations of the fivefactor model of personality and its assessment]. Zeitschrift für Differentielle und Diagnostische Psychologie, 10, 239-251.

Borkenau, P., \& Ostendorf, F. (1990). Comparing exploratory and confirmatory factor analysis: A study on the 5-factor model of personality. Personality and Individual Differences, 11, 515-524.

Boyle, G. J. (1989). Re-examination of the major personality-type factors in the Cattell, Comrey and Eysenck scales: Were the factor solutions by Noller et al. optimal? Personality and Individual Differences, 10, 1289-1299. 
Brand, C. R. (1984). Personality dimensions: An overview of modern trait psychology. In J. Nicholson \& H. Beloff (Eds.), Psychology survey (Vol. 5, pp. 175-209). Leicester: British Psychological Society.

Brand, C. R., \& Egan, V. (1989). The 'Big Five' dimensions of personality? Evidence from ipsative, adjectival self-attributions. Personality and Individual Differences, 10, 1165-1171.

Briggs, S. R. (1988). Shyness: Introversion or neuroticism? Journal of Research in Personality, 22, 290-307.

Briggs, S. R. (1989). The optimal level of measurement for personality constructs. In D. M. Buss \& N. Cantor (Eds.), Personality psychology: Recent trends and emerging directions (pp. 246-260). New York: Springer-Verlag.

Buss, A. H. (1989). Personality as traits. American Psychologist, 44, 1378-1388.

Buss, D. M. (Ed.). (1990). Biological foundations of personality: Evolution. behavioral genetics, and psychophysiology [Special issue]. Journal of Personality, 58(1).

Buss, D. M. (1991). Evolutionary personality psychology. Annual Review of Psychology, 42, 459-491.

Caspi, A., Elder, G. H., Jr., \& Bem, D. J. (1987). Moving against the world: Lifecourse patterns of explosive children. Developmental Psychology, 23, 308-313.

Cattell, R. B. (1946). The description and measurement of personality. Yonkers. NY: World Book.

Cattell, R. B., Eber, H. W., \& Tatsuoka, M. M. (1970). The handbook for the Sixteen Personality Factor Questionnaire. Champaign. IL: Institute for Personality and Ability Testing.

Cloninger, C. R. (1988). A unified biosocial theory of personality and its role in the development of anxiety states: A reply to commentaries. Psychiatric Development, 2, 83-120.

Coan, R. W. (1974). The optimal personality. New York: Columbia University Press.

Costa, P. T., Jr. (1991). Clinical use of the five-factor model: An introduction. Journal of Personality Assessment, 57, 393-398.

Costa, P. T., Jr., \& McCrae, R. R. (1976). Age differences in personality structure: A cluster analytic approach. Journal of Gerontology, 31, 564-570.

Costa, P. T., Jr., \& McCrae, R. R. (1980). Still stable after all these years: Personality as a key to some issues in adulthood and old age. In P. B. Baltes \& O. G. Brim, Jr. (Eds.), Life span development and behavior (Vol. 3, pp. 65-102). New York: Academic Press.

Costa, P. T., Jr., \& McCrae, R. R. (1985). The NEO Personality Inventory manual. Odessa, FL: Psychological Assessment Resources.

Costa, P. T., Jr., \& McCrae, R. R. (1988). From catalog to classification: Murray's needs and the five-factor model. Journal of Personality and Social Psychology, $\mathbf{5 5}$, 258-265.

Costa, P. T., Jr., \& McCrae, R. R. (1989). The NEO-PI/NEO-FFI manual supplement. Odessa, FL: Psychological Assessment Resources.

Costa, P. T., Jr., McCrae, R. R., \& Dye, D. A. (1991). Facet scales for Agreeableness and Conscientiousness: A revision of the NEO Personality Inventory. Personality and Individual Differences, 12, 887-898.

Dembroski, T. M., MacDougall, J. M., Costa, P. T., Jr., \& Grandits, G. (1989). Components of hostility as predictors of sudden death and myocardial infarction in the Multiple Risk Factor Intervention Trial. Psychosomatic Medicine, 51, 514-522. 
Depue, R. A., Krauss, S. P., \& Spoont, M. R. (1987). A two-dimensional threshold model of seasonal bipolar affective disorder. In D. Magnussen \& A. Ohman (Eds.), Psychopathology: An interactional perspective (pp. 95-123). Orlando, FL: Academic Press.

Digman, J. M. (1979, November). The five major domains of personality variables: Analysis of personality questionnaire data in the light of the five robust factors emerging from studies of rated characteristics. Paper presented at the annual meeting of the Society of Multivariate Experimental Psychology, Los Angeles.

Digman, J. M. (1985, November). The big five factors of personality: Some efforts after meaning. Paper presented at the meeting of the Society of Multivariate Experimental Psychology, Berkeley.

Digman, J. M. (1989, November). Factor redux: Re-analyses of studies of child personality. In O. P. John (Chair), The Big Five: Historical perspective and current research. Symposium conducted at the annual meeting of the Society for Multivariate Experimental Psychology, Honolulu.

Digman, J. M. (1990). Personality structure: Emergence of the five-factor model. Annual Review of Psychology, 41, 417-440.

Digman, J. M., \& Takemoto-Chock, N. K. (1981). Factors in the natural language of personality: Re-analysis, comparison, and interpretation of six major studies. Multivariate Behavioral Research. 16. 149-170.

Eysenck, H. J. (1967). The biological basis of personality. Springfield, IL: Charles C Thomas.

Eysenck, H. J., \& Eysenck, S. B. G. (1964). Manual of the Eysenck Personality Inventory. London: University Press.

Eysenck, H. J., \& Eysenck. S. B. G. (1975). Manual of the Evsenck Personality Questionnaire. San Diego: EdITS.

Eysenck, H. J., \& Eysenck, S. B. G. (1976). Psychoticism as a dimension of personality. London: Hodder and Stoughton.

Fiske, D. W. (1949). Consistency of the factorial structures of personality ratings from different sources. Journal of Abnormal and Social Psychology, 44, 329-344.

Funder, D. C. (1991). Global traits: A Neo-Allportian approach to personality. Psychological Science, 2, 31-39.

Funder, D. C., \& Colvin, C. R. (1988). Friends and strangers: Acquaintanceship. agreement, and the accuracy of personality judgment. Journal of Personality and Social Psychology, 55, 149-158.

Funder, D. C., \& Colvin, C. R. (in press). Congruence of self and others' judgments of personality. In S. R. Briggs, R. Hogan, \& W. H. Jones (Eds.), Handbook of personality psychology. New York: Academic Press.

Goldberg, L. R. (1971). A historical survey of personality scales and inventories. In P. McReynolds (Ed.), Advances in psychological assessment (Vol. 2. pp. 293-336). Palo Alto, CA: Science and Behavior Books.

Goldberg, L. R. (1981). Language and individual differences: The search for universals in personality lexicons. In $\mathrm{L}$. Wheeler (Ed.), Review of personality and social psychology (Vol. 2, pp. 141-165). Beverly Hills: Sage.

Goldberg, L. R. (1982). From ace to zombie: Some explorations in the language of personality. In C. D. Spielberger \& J. N. Butcher (Eds.), Advances in personality assessment (Vol. 1, pp. 203-234). Hillsdale. NJ: Lawrence Erlbaum. 
Goldberg, L. R. (1989, June). Standard markers of the Big Five factor structure. Paper presented at the First International Workshop on Personality Language, Groningen, The Netherlands.

Goldberg, L. R. (1990). An alternative "description of personality": The Big-Five factor structure. Journal of Personality and Social Psychology, 59, 1216-1229.

Gough, H. G. (1987). California Psychological Inventory administrator's guide. Palo Alto, CA: Consulting Psychologists Press.

Gough, H. G., \& Heilbrun, A. B., Jr. (1983). Adjective Check List manual. Palo Alto, CA: Consulting Psychologists Press.

Graziano, W. G., \& Eisenberg. N. H. (in press). Agreeableness: A dimension of personality. In S. R. Briggs, R. Hogan, \& W. H. Jones (Eds.). Handbook of personality psychology. New York: Academic Press.

Guilford, J. P. (1977). Will the real factor of extraversion-introversion please stand up? A reply to Eysenck. Psychological Bulletin, 84, 412-416.

Guilford, J. S., Zimmerman, W. S., \& Guilford, J. P. (1976). The Guilford-Zimmerman Temperament Survey Handbook: Twenty-five years of research and application. San Diego: EdITS.

Hofstee. W. K. B., \& Van Heck, G. L. (Eds.). (1990). Personality language [Special issue]. European Journal of Personality, 4(2).

Hogan, R. (1983). Socioanalytic theory of personality. In M. M. Page (Ed.), 1982 Nebraska Symposium on Motivation: Personality-current theory and research (pp. 55-89). Lincoln: University of Nebraska Press.

Hogan, R. (1986). Hogan Personality Inventory manual. Minneapolis: National Computer Systems.

Hogan, R. (1987). Personality psychology: Back to basics. In J. Aronoff, A. I. Rabin, \& R. A. Zucker (Eds.). The emergence of personality (pp. 79-104). New York: Springer.

Hogan, R. (in press). Personality and personality measurement. In M. D. Dunnette \& L. Hough (Eds.), Handbook of industrial/organizational psychology. Palo Alto, CA: Consulting Psychologists Press.

Hyland, M. E. (1985). Do person variables exist in different ways? American Psychologist, 40, 1003-1010.

Jackson. D. N. (1984). Personality Research Form manual (3rd. ed.). Port Huron, MI: Research Psychologists Press.

John. O. P. (1989a, November). Big Five prototypes for the Adjective Check List using observer data. In O. P. John (Chair), The Big Five: Historical perspective and current research. Symposium conducted at the annual meeting of the Society for Multivariate Experimental Psychology, Honolulu.

John, O. P. (1989b). Towards a taxonomy of personality descriptors. In D. M. Buss \& N. Cantor (Eds.), Personality psychology: Recent trends and emerging directions (pp. 261-271). New York: Springer-Verlag.

John, O. P. (1990a). The "Big Five" factor taxonomy: Dimensions of personality in the natural language and in questionnaires. In L. Pervin (Ed.), Handbook of personality theory and research (pp. 66-100). New York: Guilford.

John, O. P. (1990b). The search for basic dimensions of personality: A review and critique. In P. McReynolds, J. C. Rosen, \& G. L. Chelune (Eds.), Advances in psychological assessment (Vol. 7, pp. 1-37). New York: Plenum. 
John, O. P., Angleitner, A., \& Ostendorf, F. (1988). The lexical approach to personality: A historical review of trait taxonomic research. European Journal of Personality, 2, 171-203.

Jung, C. G. (1971). Psychological types (H. G. Baynes, Trans., revised by R. F. C. Hull). Princeton: Princeton University Press. (Original work published 1923)

Kamp, J., \& Gough, H. G. (1986, August). The Big Five personality factors from an assessment context. Paper presented at the annual convention of the American Psychological Association, Washington, DC.

Kelly, E. L., \& Conley, J. J. (1987). Personality and compatibility: A prospective analysis of marital stability and marital satisfaction. Journal of Personality and Social Psychology, 52, 27-40.

Kenny, D. A. (1991). A general model of consensus and accuracy in interpersonal perception. Psychological Review, 98, 155-163.

Kluckhohn, C., \& Murray, H. A. (1953). Personality formation: The determinants. In C. Kluckhohn, H. A. Murray, \& D. M. Schneider (Eds.), Personality in nature, society, and culture. New York: Knopf.

Krug, S. E., \& Johns, E. F. (1986). A large-scale cross-validation of the second-order personality structure defined by the 16PF. Psychological Reports, 59, 683-693.

Lanning, K., \& Gough, H. G. (1991). Shared variance in the California Psychological Inventory and the California Q-Set. Journal of Personality and Social Psychology, 60, 596-606.

Leary, T. (1957). Interpersonal diagnosis of personality. New York: Ronald Press.

Little, B. R. (1989). Personal Projects Analysis: Trivial pursuits, magnificent obsessions and the search for coherence. In D. M. Buss \& N. Cantor (Eds.), Personality psychology: Recent trends and emerging directions (pp. 15-31). New York: Springer-Verlag.

Loehlin, J. C. (1987). Heredity, environment, and the structure of the California Psychological Inventory. Multivariate Behavioral Research, 22, 137-148.

Loevinger, J. (1966). The meaning and measurement of ego development. American Psychologist, 21, 195-206.

Lorr, M. (1978). The structure of the California Q-Set. Multivariate Behavioral Research, 13, 387-393.

McCrae, R. R. (1987). Creativity, divergent thinking, and openness to experience. Journal of Personality and Social Psychology, 52, 1258-1265.

McCrae, R. R. (1989). Why I advocate the five-factor model: Joint analyses of the NEO-PI and other instruments. In D. M. Buss \& N. Cantor (Eds.), Personality psychology: Recent trends and emerging directions (pp. 237-245). New York: SpringerVerlag.

McCrae, R. R. (1990). Traits and trait names: How well is Openness represented in natural languages? European Journal of Personality, 4, 119-129.

McCrae, R. R. (1991). The five-factor model and its assessment in clinical settings. Journal of Personality Assessment, 57, 399-414.

McCrae, R. R., \& Costa, P. T., Jr. (1985a). Comparison of EPI and Psychoticism scales with measures of the five-factor model of personality. Personality and Individual Differences, 6, 587-597.

McCrae, R. R., \& Costa, P. T., Jr. (1985b). Openness to experience. In R. Hogan \& W. H. Jones (Eds.), Perspectives in personality (Vol. 1. pp. 145-172). Greenwich, CT: JAI Press. 
McCrae, R. R., \& Costa, P. T., Jr. (1985c). Updating Norman's "adequate taxonomy": Intelligence and personality dimensions in natural language and in questionnaires. Journal of Personality and Social Psychology, 49, 710-721.

McCrae, R. R., \& Costa, P. T., Jr. (1987). Validation of the five-factor model of personality across instruments and observers. Journal of Personality and Social Psychology, 52, 81-90.

McCrae, R. R., \& Costa, P. T., Jr. (1989a). Reinterpreting the Myers-Briggs Type Indicator from the perspective of the five-factor model of personality. Journal of Personality, 57, 17-40.

McCrae, R. R., \& Costa, P. T., Jr. (1989b). Rotation to maximize the construct validity of factors in the NEO Personality Inventory. Multivariate Behavioral Research, 24, 107-124.

McCrae, R. R., \& Costa, P. T., Jr. (1989c). The structure of interpersonal traits: Wiggins's circumplex and the five-factor model. Journal of Personality and Social Psychology, 56, 586-595.

McCrae, R. R., \& Costa, P. T., Jr. (1990). Personality in adulthood. New York: Guilford.

McCrae, R. R., \& Costa, P. T., Jr. (1991). The NEO Personality Inventory: Using the five-factor model in counseling. Journal of Counseling and Development, 69, 367-372.

McCrae, R. R., \& Costa, P. T., Jr. (in press). Conceptions and correlates of Openness to Experience. In S. R. Briggs, R. Hogan, \& W. H. Jones (Eds.), Handbook of personality psychology. New York: Academic Press.

McCrae, R. R., Costa, P. T., Jr., \& Busch, C. M. (1986). Evaluating comprehensiveness in personality systems: The California Q-Set and the five-factor model. Journal of Personality, 54, 430-446.

McCrae, R. R., Piedmont, R. L., \& Costa, P. T., Jr. (1990, August). The CPI and the five-factor model: Rational and empirical analyses. Paper presented at the annual convention of the American Psychological Association, Boston.

Mershon, B., \& Gorsuch, R. L. (1988). Number of factors in the personality sphere: Does increase in factors increase predictability of real-life criteria? Journal of Personality and Social Psychology, 55, 675-680.

Miller, G. E. (1956). The magical number seven, plus-or-minus two: Some limits on our capacity for processing information. Psychological Review, 63, 81-97.

Millon, T. (1983). Millon Clinical Multiaxial Inventory manual (3rd ed.). Minneapolis: Interpretive Scoring Systems.

Murray, H. A. (1938). Explorations in personality. New York: Oxford University Press.

Mutén, E. (1991). Self-reports, spouse ratings, and psychophysiological assessment in a behavioral medicine program: An application of the five-factor model. Journal of Personality Assessment, 57, 449-464.

Myers, I. B., \& McCaulley, M. H. (1985). Manual: A guide to the development and use of the Myers-Briggs Type Indicator. Palo Alto, CA: Consulting Psychologists Press.

Noller, P., Law, H. \& \& Comrey, A. L. (1987). Cattell, Comrey, and Eysenck personality factors compared: More evidence for the five robust factors? Journal of Personality and Social Psychology, 53, 775-782.

Norman, W. T. (1963). Toward an adequate taxonomy of personality attributes: Replicated factor structure in peer nomination personality ratings. Journal of Abnormal and Social Psychology, 66, 574-583. 
Norman, W. T. (1969). “To see oursels as ithers see us!": Relations among selfperceptions, peer-perceptions, and expected peer-perceptions of personality attributes. Multivariate Behavioral Research, 4, 417-443.

Ostendorf, F. (1990). Sprache und Persönlichkeitsstruktur: Zur Validität des FünfFaktoren-Modells der Persönlichkeit [Language and personality structure: Toward the validation of the five-factor model of personality]. Regensburg, Germany: S. Roderer Verlag.

Peabody, D. (1987). Selecting representative trait adjectives. Journal of Personality and Social Psychology, 52, 59-71.

Peabody, D., \& Goldberg, L. R. (1989). Some determinants of factor structures from personality-trait descriptors. Journal of Personality and Social Psychology, 57, 552567.

Piedmont, R. L., McCrae, R. R., \& Costa, P. T., Jr. (1991). Adjective Check List scales and the five-factor model. Journal of Personality and Social Psychology, 60 , $630-637$.

Plomin, R., \& McClearn, G. E. (1990). Human behavioral genetics of aging. In J. E. Birren \& K. W. Schaie (Eds.), Handbook of the psychology of aging (3rd ed.. pp. 67-78). New York: Academic Press.

Read, S. J., Jones, D. K., \& Miller, L. C. (1990). Traits as goal-based categories: The importance of goals in the coherence of dispositional categories. Journal of Personality and Social Psychology, 58, 1048-1061.

Rogers, C. R. (1961). On becoming a person: A therapist's view of psychotherapy. Boston: Houghton Mifflin.

Rokeach, M. (1960). The open and closed mind. New York: Basic Books.

Rushton, J. P., Fulker, D. W., Neale, M. C., Nias, D. K. B.. \& Eysenck, H. J. (1986). Altruism and aggression: The heritability of individual differences. Journal of Personality and Social Psychology, 50, 1192-1198.

Sullivan, H. S. (1953). The interpersonal theory of psychiatry. New York: Norton.

Tellegen, A. (1982). Brief manual for the Differential Personality Questionnaire. Unpublished manuscript, University of Minnesota.

Tellegen, A. (in press). Personality traits: Issues of definition, evidence and assessment. In D. Cicchetti \& W. Grove (Eds.), Thinking clearly about psychology: Essays in honor of Paul Everett Meehl. Minneapolis: University of Minnesota Press.

Tellegen, A., \& Atkinson, G. (1974). Openness to absorbing and self-altering experiences ("absorption"), a trait related to hypnotic susceptibility. Journal of Abnormal Psychology, 83, 268-277.

Tellegen, A., \& Waller, N. G. (in press). Exploring personality through test construction: Development of the Multidimensional Personality Questionnaire. In S. R. Briggs \& J. M. Cheek (Eds.), Personality measures: Development and evaluation (Vol. 1). Greenwich, CT: JAI Press.

Thomae, H. (1989, July). How European is personality psychology in Europe? Invited lecture, 1st European Congress of Psychology, Amsterdam.

Thorne, A. (1987). The press of personality: Conversations between introverts and extraverts. Journal of Personality and Social Psychology, 53, 718-726.

Tooby, J., \& Cosmides, L. (1990). On the universality of human nature and the uniqueness of the individual: The role of genetics and adaptation. Journal of Personality. 58. $17-68$. 
Trapnell, P. D., \& Wiggins, J. S. (1990). Extension of the Interpersonal Adjective Scales to include the Big Five dimensions of personality (IASR-B5). Journal of Personality and Social Psychology, 59, 781-790.

Tupes, E. C., \& Christal, R. E. (1961). Recurrent personality factors based on trait ratings (USAF ASD Tech. Rep. No. 61-97). Lackland Air Force Base, TX: U.S. Air Force.

Waller, N. G., \& Ben-Porath, Y. S. (1987). Is it time for clinical psychology to embrace the five-factor model of personality? American Psychologist, 42, 887-889.

Watson, D., \& Clark, L. A. (1984). Negative affectivity: The disposition to experience aversive emotional states. Psychological Bulletin, 96, 465-490.

Watson, D., \& Clark, L. A. (in press). Extraversion and its positive emotional core. In S. R. Briggs, W. H. Jones, \& R. Hogan (Eds.), Handbook of personality psychology. New York: Academic Press.

Wiggins, J. S. (1968). Personality structure. Annual Review of Psychology, 19, 293 350 .

Wiggins, J. S. (1979). A psychological taxonomy of trait-descriptive terms: The interpersonal domain. Journal of Personality and Social Psychology, 37, 395-412.

Wiggins, J. S. (in press). Agency and communion as conceptual coordinates for the understanding and measurement of interpersonal behavior. In D. Cicchetti \& W. Grove (Eds.), Thinking clearly about psychology: Essays in honor of Paul Everett Meehl. Minneapolis: University of Minnesota Press.

Wiggins, J. S., \& Pincus, A. L. (1989). Conceptions of personality disorders and dimensions of personality. Psychological Assessment: A Journal of Consulting and Clinical Psychology, 1, 305-316.

Wiggins, J. S. , \& Trapnell, P. D. (in press). Personality structure: The return of the Big Five. In S. R. Briggs, R. Hogan, \& W. H. Jones (Eds.), Handbook of personality psychology. New York: Academic Press.

Yang, K., \& Bond, M. H. (1990). Exploring implicit personality theories with indigenous or imported constructs: The Chinese case. Journal of Personality and Social Psychology, 58, 1087-1095.

Zonderman, A. B., Stone, S. V., \& Costa, P. T., Jr. (1989, August). Age and neuroticism as risk factors for the incidence of diagnoses of psychotic and neurotic disorders. Paper presented at the annual convention of the American Psychological Association, New Orleans.

Zuckerman, M. (1984). Sensation seeking: A comparative approach to a human trait. Behavioral and Brain Sciences, 7, 413-471.

Zuckerman, M., Kuhlman, D. M., \& Camac, C. (1988). What lies beyond E and $\mathrm{N}$ ? Factor analyses of scales believed to measure basic dimensions of personality. Journal of Personality and Social Psychology, 54, 96-107.

Zuckerman, M., Bernieri, F., Koestner, R., \& Rosenthal, R. (1989). To predict some of the people some of the time: In search of moderators. Journal of Personality and Social Psychology, 57, 279-293.

Manuscript received October 1, 1990; revised May 9. 1991. 
This document is a scanned copy of a printed document. No warranty is given about the accuracy of the copy. Users should refer to the original published version of the material. 